\title{
d Which injuries may indicate child abuse?
}

\author{
S Maguire
}

\begin{abstract}
Correspondence to
Dr S Maguire, Department of Child Health, Wales College of Medicine, Cardiff University, Heath Park, Cardiff CF 14 4XN, UK; sabinemaguire@yahoo.co.uk
\end{abstract}

Accepted 18 July 2010 Published Online First 6 October 2010

\begin{abstract}
Making the decision as to whether an injury is a result of child abuse or not is stressful for both the family involved and the clinical team. It is not a decision that is taken lightly, and with an increasing expectation by the investigating agencies, lawyers and the public in general, to ensure that it is based on explicit 'evidence', clinicians need to be up to date with the latest scientific publications in the field. This article aims to summarise the current evidence in relation to all physical injuries except those pertaining to the central nervous system, which will form a separate article. It will examine the pattern of accidental and abusive bruises, fractures, burns, abdominal injuries and oral injuries focusing on discriminating features and necessary investigations.
\end{abstract}

\section{WHICH CHILDREN ARE MORE LIKELY TO SUSTAIN PHYSICAL ABUSE?}

The literature consistently records that the youngest children (predominantly $<3$ years) are most likely to be physically abused, although it is not restricted to this age group, as those up to late teens are also recorded as being abused. ${ }^{12}$ Children aged $<1$ year experience the highest rate of abuse (21.9 per 1000 children). ${ }^{3}$ Sociodemographic characteristics vary from one country to another, with lower socioeconomic status having a greater association with physical abuse in many North American studies, ${ }^{4}$ and a suggestion of increased prevalence of abuse among immigrant children (these children are eight times more likely to be reported as abused in Sweden ${ }^{2}$ ), asylum seekers ${ }^{5}$ and internationally adopted children. ${ }^{6}$ This reiterates the need to be aware of all the sociodemographic circumstances of the child. It is difficult to identify whether there is a true association between abuse and specific social factors, as opposed to increased reporting/recognition of abuse in certain groups in society. Certain characteristics in the children themselves may render them more vulnerable to abuse, including disability, and in particular behavioural or learning difficulties, ${ }^{7} 8$ while practitioners may operate lower thresholds for referral of certain minority groups. ${ }^{3}$

\section{WHICH BRUISES SUGGEST AN ABUSIVE AETIOLOGY?}

Bruising remains the commonest abusive injury encountered, ${ }^{9}$ with the head and neck being the most commonly recorded site. ${ }^{10}$ However, children will always sustain bruises as a consequence of simple accidents, so distinguishing these two situations is key. ${ }^{10}$ Contrary to popular belief, boys do not sustain more bruises than girls. ${ }^{11-14}$ It is clear from the literature that the pattern of accidental bruising in young children is strongly influenced by their level of independent mobility, with non-mobile infants least likely to sustain accidental bruises (prevalence $<1 \%$ ). ${ }^{13}$ Thorough investigation of a baby with an unexplained or inadequately explained bruise is essential, as some may have underlying coagulopathies while others may have been abused. ${ }^{15}$

Once children start to move around independently, bruising increases incrementally (prevalence: crawling, cruising $17 \%$, or walking $>50 \%$ ). However, even in these children, the bruising tends to be found in specific locations (see figure 1). The commonest site for accidental bruises in mobile children is the knees/shins. ${ }^{14}{ }^{16}$ In young children $(<6$ years), accidental bruising to the head occurs predominantly in a ' $T$ ' shape across the forehead, nose, upper lip and chin, and in more than a third $(37 \%)$ bruising is also found on the back of the head. ${ }^{17}$ It has been clearly shown that accidental bruising occurs on the front of the body and over bony prominences and $<6 \%$ of accidental bruises to the face are found on the cheeks or periorbital area. ${ }^{11} 1317$ In contrast, abusive bruises are found predominantly on the head and neck, where the bruising occurs on the ear, neck and cheeks, all of which are extremely rare sites of accidental bruises (figure 2). ${ }^{918} 19$ Any part of the body may be bruised as a consequence of abuse, but specific areas such as the forearms, upper limb and adjoining area of trunk, or outside thigh may indicate 'defensive bruising' where the child has tried to protect themselves from the blows being rained upon them. ${ }^{920}$ Occasionally an abusive bruise may be explicitly linked to its aetiology, if there is a positive or negative imprint of the weapon (eg, studded dog collar, belt buckle) ${ }^{21}$; however, the tracking of bruising may distort the precise location of the original injury (eg, vertical gluteal cleft bruising when the child was struck horizontally ${ }^{22}$.

It has recently emerged that the presence of petechiae in association with bruises is a strong predictor of abusive injury with a positive predictive value of 80 (95\% CI 64.1 to 90.1), although their absence is of no diagnostic value. Thus it is important to examine carefully for the presence of petechiae with bruising. ${ }^{12}$ As with all injuries, other differential diagnoses must be carefully considered, including coagulation disorders, Mongolian blue spots ${ }^{23}$ (which can occur on the 


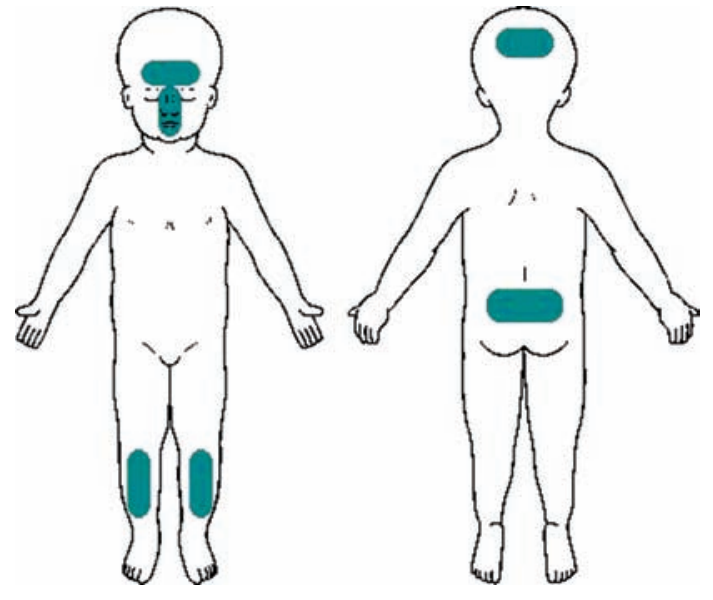

Figure 1 Accidental bruising patterns.

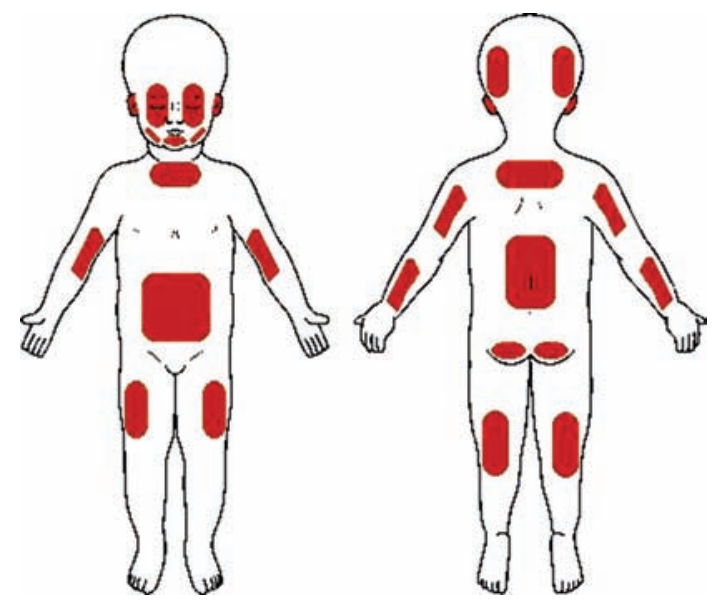

Figure 2 Abusive bruising patterns.

back, knee, scalp and feet as well as the lumbosacral area), Henoch-Schonlein purpura, hair braiding, ${ }^{24}$ etc (box 1).

It has long been the practice of clinicians to offer a likely age for bruises found, and this is relied on heavily by the investigating team of social workers and police. Some authors still give explicit timetables for the appearance of different colours (red, blue, yellow, green) in bruises ${ }^{25}$; however, it has been clearly established that there is no scientific basis for such a timeline, ${ }^{26}$ and as such a personal estimation may be extremely misleading. It is clear that not only do different colours appear in the same bruise at the same time, but each of us perceives colour differently, and we may not even agree with our own assessment of colour between the assessment of the live child and subsequent review of a photograph. ${ }^{27-29} \mathrm{New}$ techniques are being explored which may offer a method of dating bruises, including reflectance spectroscopy, chromophore concentrations, etc, but these are not yet in clinical practice. ${ }^{3031}$

\section{COULD THIS MARK BE A BITE?}

Abusive bites are particularly important injuries to identify in children, as they are the only physical injury which offers the potential for a forensic

\section{Box 1 Evaluating bruises}

Assessing a bruise of possible abusive aetiology

- Document location, number, size (two maximum diameters), petechiae if present and history of cause (if any given)

- Photograph relevant bruises, including a right angled measuring device, and colour scale in the photo

- Full blood count, coagulation studies, von Willebrand Factor, PF A 100

- Family/personal history of bleeding disorder? Discuss with haematologists

- Age $<2$ years? Consider other occult injury (fractures, retinal haemorrhage, intracranial abnormality)

identification of the perpetrator. ${ }^{32}$ This may include reconstruction of the dentition of the perpetrator of the bite, with or without additional DNA evidence. However, this relies on the initial examining doctor recognising that the injury could be a bite. Children are frequently bitten, predominantly by animals or other children. Dog bites are typically narrow, and they produce a tearing injury. Any adult bite on a child sufficient to leave a mark is deemed abusive. An adult bite classically results in a $2-5 \mathrm{~cm}$ oval or circular mark, made by two opposing concave arcs, with or without associated ecchymosis and/ or petechiae. However, the bite may be incomplete, located over a curved surface or be a dragging injury, distorting this shape. Traditionally, the method of distinguishing between an adult (and thus abusive) bite or a child bite, relies on measuring the intercanine distance within the bite, which in human adult bites are deemed to be $3.0-4.5 \mathrm{~cm}$; $2.5-3.0 \mathrm{~cm}$ in a child or small adult; and $<2.5 \mathrm{~cm}$ in a child. However, it is important to bear in mind that there can be considerable racial, sexual or individual variations and that adult dentition is reached by 12 years. In addition, if the adult has distorted dental anatomy, their intercanine distance may be reduced. Likewise, another important facet to bites, is that a child who is being attacked may also bite their attacker, which may help in their identification. ${ }^{33}$ The full analysis of a bite therefore is a specialised field, as consideration must also be given to a differential diagnosis such as skin conditions-for example, ringworm (box 2).

\section{WHICH FRACTURES MAY BE THE RESULT OF ABUSE?}

Fractures are a common injury in childhood, with between a third and two-thirds of boys and $40 \%$ of girls sustaining a fracture by their 15 th birthday. 3435 Many are related to falls, motor vehicle collisions, playground or sporting activities, ${ }^{34}$ and most frequently involve the upper limb. ${ }^{35}$ Distinguishing the inflicted from the accidental fracture is challenging, but this is an injury where the age of the 


\section{Box 2 Evaluating possible bites}

If you suspect that an injury may be a bite then you must do the following:

- Obtain clinical photographs of the bite, in each plane if it is on a curved surface

- A right angled measuring device must be included in the photograph, consider serial (daily) photographs if there is going to be a delay before forensic dental assessment

- Contact a forensic dentist immediately via the British Association of Forensic Odontologists (http://www.bafo.org.uk)

child seems to be a key factor. A large-scale casecontrol UK study has shown ${ }^{36}$ that $85 \%$ of accidental fractures occur in children $>5$ years, while $80 \%$ of abusive fractures occur in children $<18$ months. This pattern is borne out in US data too, where it is noted that while the incidence of abusive fractures is $15.3 / 100000$ children aged $0-35$ months, the incidence in those $<12$ months is $36.1 / 100000$ dropping to $4.8 / 100000$ for those aged $12-35$ months, respectively. ${ }^{37}$ Determining how many abused children have fractures (occult or overt) is more difficult, as not all children being assessed for possible abuse undergo standardised investigations to detect fractures. Overall, it is estimated that a third of abused children have fractures, ${ }^{38} 39$ many of which are occult. ${ }^{40}$ One finding that is clear across all studies, is that multiple fractures have a strong association with abuse. ${ }^{3637}$ The biomechanics of fractures is a complex subject (well reviewed by Pierce and Bertocci ${ }^{41}$ ), but it is becoming increasingly clear that if clinicians are to make even the crudest estimate of the likelihood that the fracture found can be explained by the history offered, we need to be much more 'forensic' in our recording of the incident. Specifically, when presented with a fracture due to an alleged fall, it is important to document the fall height, weight of the child, surface on which the child landed and the way in which they landed to at least estimate the likelihood that the injuries found can be explained by the history given.

\section{WHICH FRACTURES CAUSE THE MOST CONCERN?}

As with bruising, the level of independent mobility of a child is an important aspect of your assessment of fractures. Children who are not yet walking, are far less likely to sustain accidental long-bone fractures. ${ }^{42} 43$ Overall, the probability that a femoral fracture in a child is due to abuse is $28 \%$ (95\% CI $15 \%$ to $44 \%$ ), but the majority of abusive femoral fractures are in younger children, particularly those aged $<1$ year. ${ }^{44}$ While spiral fractures of the femur are the commonest femoral fractures referred under the child protection procedures, they are only recorded as the commonest abusive fracture in children $<15$ months of age. ${ }^{45}$
Overall, the commonest accidental and abusive fracture of the femur is a mid-shaft fracture. ${ }^{44}$ The published data in relation to determining the precise probability of abuse for metaphyseal fractures are sparse, but in relation to the lower limb, they are certainly more commonly due to abuse than other causes $(p<0.001) .{ }^{46}$

Humeral fractures in children aged $<3$ years, have a probability of abuse of $48 \%(95 \%$ CI $6 \%$ to $94 \%),{ }^{44}$ but here age $<15$ months versus age $15-36$ months, seems a strong predictor of abusive fractures. ${ }^{47}$ In addition, fracture type is a key element, as supracondylar fractures of the humerus are far more likely to be accidental (though not exclusively so). ${ }^{48}$ The commonest abusive fractures, on the other hand, are spiral or oblique fractures (in children $<5$ years old). ${ }^{4749}$

Skull fractures are a common fracture in young children, with $80 \%$ of accidental and $88 \%$ of abusive skull fractures occurring in infants under 1 year of age. ${ }^{49}$ Thus, although the probability of abuse for a skull fracture is 30\% (95\% CI 19\% to $46 \%$ ), there are few distinguishing features. The commonest accidental and abusive skull fractures are linear, and usually parietal. ${ }^{50} 51$ The significance of complex, multiple, diastatic or depressed skull fractures is difficult to define, as published data are conflicting. ${ }^{50-52}$

The fractures with the highest specificity for abuse are clearly rib fractures (probability of abuse of $71 \%, 95 \%$ CI $42 \%$ to $91 \%$ ). These are a rare accidental fractures, but may occur as a consequence of metabolic bone disease, birth injuries or major trauma. ${ }^{53-55}$ Multiple rib fractures, in the absence of a history of bone disease, or major trauma are highly specific for abuse. ${ }^{46}$ There has been considerable emphasis on the association between abuse and fracture location in rib fractures. While posterior rib fractures raise concerns of abuse immediately, overall, anterior rib fractures are commoner in abuse, while lateral rib fractures are more common in non-abused children. ${ }^{54} 56$ Cardiopulmonary resuscitation (CPR) has been proposed as a possible cause of rib fractures, potentially creating diagnostic confusion where a child has presented collapsed, with injuries later thought to be abusive. The current published evidence suggests that CPR is a rare cause of rib fractures, and when they do occur they tend to be anterior and may be multiple, but do not occur posteriorly. ${ }^{57}$ However, the current CPR method proposed by Advanced Paediatric Life Support (includes encircling the chest with the hands, and no studies have yet been conducted to determine the risk of rib fractures from this method.

\section{HOW ARE OCCULT FRACTURES BEST DETECTED?}

All children $<2$ years of age with suspected physical abuse should have a full skeletal survey (SS) performed. Both the recently agreed standards for radiological investigations of suspected non-accidental injury by the Royal College of Paediatrics and Child Health and the Royal College of Radiology ${ }^{58}$ and the American Academy of 
Pediatrics $^{59}$ are explicit about the standard of SS that must be conducted if occult fractures are to be identified, or excluded. This involves 19 images, and must include oblique views of the ribs, which have been clearly shown to enhance the detection of rib fractures, particularly posterior rib fractures. ${ }^{60} 61$ In addition, it is clear that acute fractures may be missed on SS, or equivocal findings may be misinterpreted as fractures, and as such a single SS may not be adequate. ${ }^{62}$ If an initial SS is negative or equivocal, but concerns remain then consideration should be given to either conducting a radionuclide bone scan (RNI) in addition, ${ }^{62}$ or a follow-up SS 11-14 days later. ${ }^{6364}$ The advantage of a RNI, is that it can be performed at the same time as the original SS, thus avoiding any concerns surrounding the child protection status of the child on discharge, and fractures become apparent on RNI within $4 \mathrm{~h}$ of occurring ${ }^{65}$ However, the drawbacks are that not all units can perform or interpret such scans in young children, and certain fractures such as skull or metaphyseal fractures are less accurately defined.

Clearly if unexplained fractures are identified in any child, then consideration must be given to any predisposing factors such as a history of osteogenesis imperfecta, prematurity, chronic disease with possible associated rickets, and other metabolic diseases, and where appropriate, investigations should be performed to identify/exclude such conditions.

\section{WHEN DOES A BURN RAISE SAFEGUARDING CONCERNS?}

Burns are a common cause of emergency department attendances, particularly in children $<5$ years of age. ${ }^{66}$ Within this age group, mortality from burns is also highest, and the survivors may have significant physical and psychological morbidity. Boys uniformly have more burns than girls (2:1 overall, but nearly double this for children aged 10-14 years). ${ }^{66}$ While in the Western world, scalds are the predominant burn type, ${ }^{66}$ in developing countries where gas cylinders are a common cooking utensil, flame burns are by far the commonest type. ${ }^{67}$ The true prevalence of intentional burns is difficult to determine, and is estimated to range between $10 \%$ and $12 \%$ of abused children. 6869 What percentage of children admitted to burns units have sustained an intentional burn is unclear, with estimates varying between $1 \%$ and $35 \% .{ }^{70}$ However, it has been suggested that burns resulting from neglect, outnumber intentional burns by $9: 1 .^{71}$

\section{DISTINGUISHING INTENTIONAL SCALDS FROM ACCIDENTAL SCALDS}

Accidental scalds in young children are predominantly 'pull over' scalds, where the child pulls down a container of hot liquid on themselves, giving rise to a classical pattern of scald burns affecting the upper limb, face, anterior trunk, and/or neck (see figure 3$).^{72}$ These burns are usually asymmetric, and have an irregular edge, and irregular burn depth. Children may also fall accidentally into a hot cooking liquid. An increasing number of scalds are occurring when older children spill food/drinks straight from the microwave. ${ }^{73}$ Hot tap water may be a factor in accidental scalds, particularly where there is no legislation about domestic hot water temperature (as in the UK), given that it only takes $1 \mathrm{~s}$ for an infant to sustain a full-thickness burn from a liquid at $60^{\circ} \mathrm{C} .{ }^{74}$

In contrast to the accidental scalds, the intentional ones documented in the literature are predominantly hot water immersion scalds, involving lower limbs, and/or perineum/buttocks, due to immersion injuries (see figure 4). There may be 'glove and stocking' burns to hands and feet (figure 5). A single upper limb, or more rarely the whole face may also be involved. Key distinguishing characteristics are that the burn has clear upper limits, is of consistent burn depth, and is symmetrical, in contrast to the accidental scalds. ${ }^{70}$ Other worrying features are skinfold sparing, presence of other unrelated injuries, previous burns, occult fractures, associated neglect, sibling being blamed and the family already known to social services. However, the current world literature is predominantly drawn from

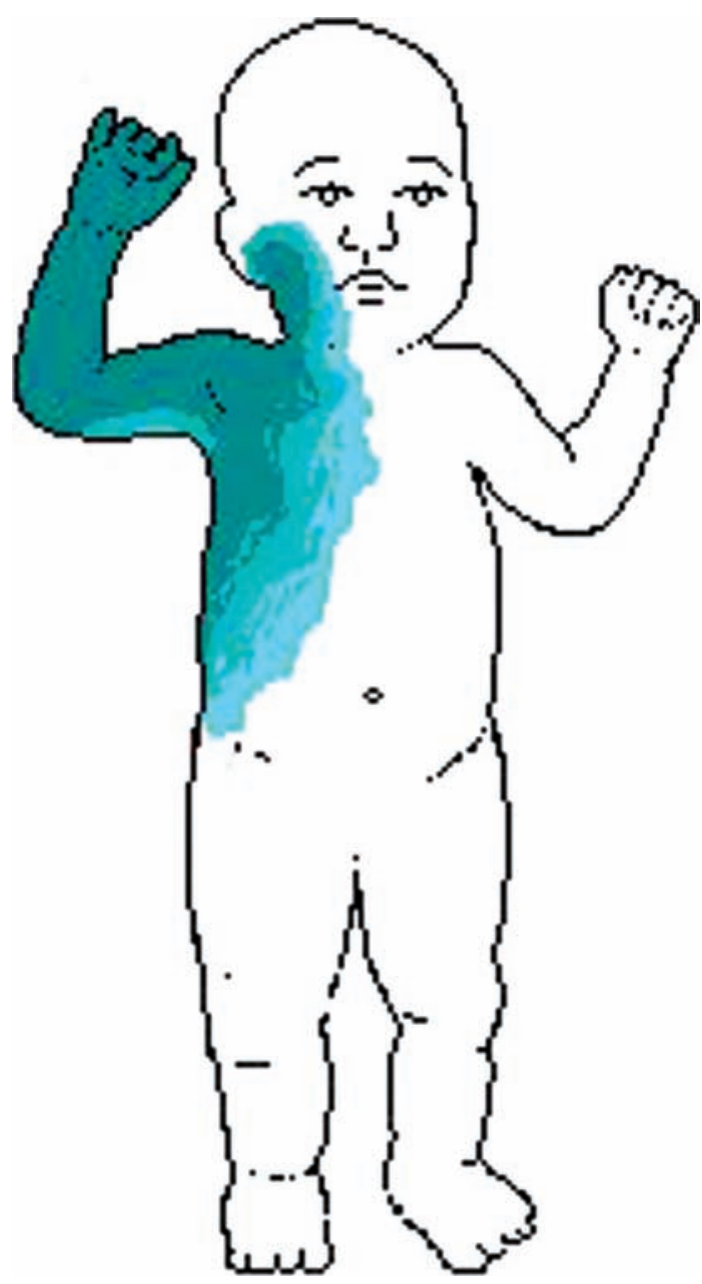

Figure 3 Accidental scald pattern. 


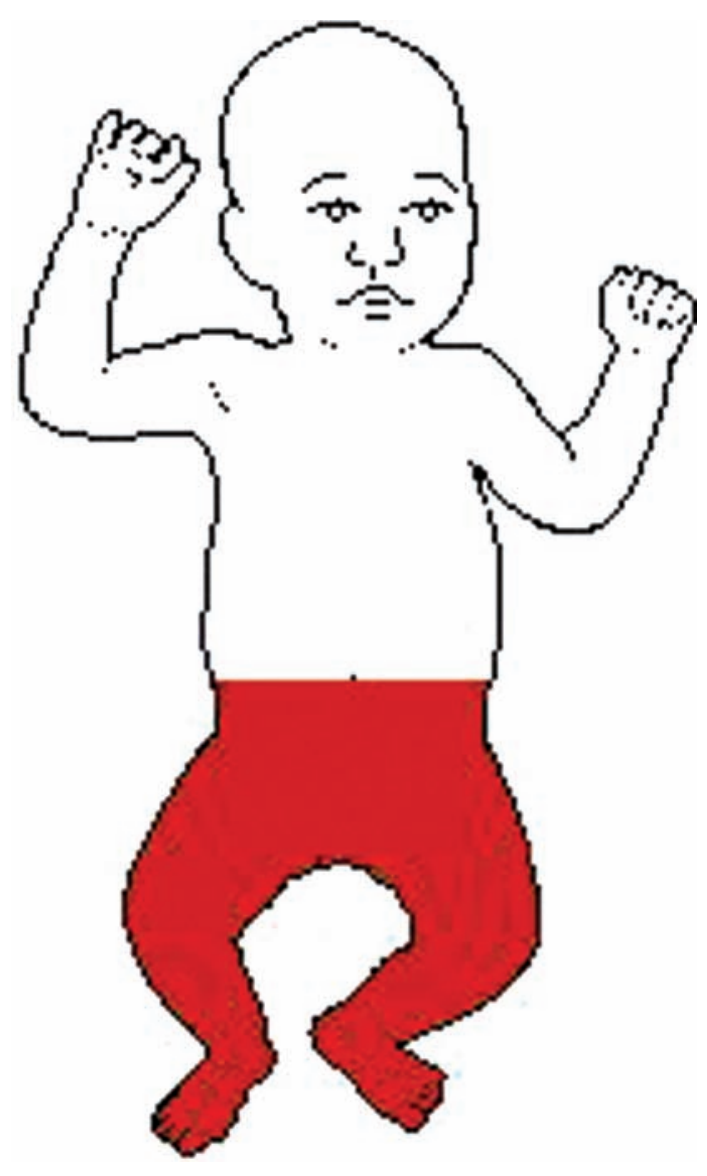

Figure 4 Abusive scald pattern.

burns unit admissions, and may not reflect the pattern of accidental or abusive scalds which are less severe.

The other major burns that children may sustain accidentally or abusively are thermal burns (from flames or hot surfaces). These account for the second largest group of burns in young children. ${ }^{7576}$ These tend to be on the palm of the hands, particularly in toddlers. There has been an increase in contact burns due to heated hair devices (eg, curling tongs, hair straighteners) recently, and these may cause initial concern as the burn may be on both the palm and dorsum of the hand or foot. ${ }^{77}$ These are commonest in toddlers who have had access to devices used by older children, where the device can stay extremely hot for more than 10 min after being switched off. Intentional contact burns tend to be full thickness, affecting the back or neck, have a clear demarcated edge, and it may be possible to match the burn to a household item which has been used to inflict the injury. ${ }^{5678}$ In contrast to scalds, these intentional burns occur throughout all ages in childhood.

When assessing potentially inflicted burns the precise history, supplemented if necessary by a home visit (eg, to check domestic water temperature, measure the height of the side of the bath, find relevant household electrical devices, etc), is absolutely crucial. A number of conditions have been mistaken for abuse, including infections such as impetigo, ${ }^{79}$ scalded skin syndrome, ${ }^{80}$

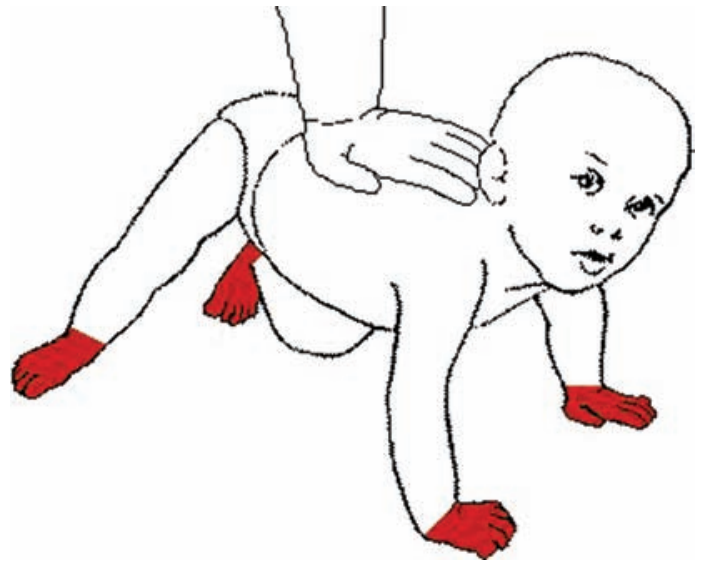

Figure 5 Abusive scald 'glove and stocking' pattern.

photodermatitis (particularly where a child has had contact with a psoralen such as lime juice, or rue and is then exposed to the sun, and over the next $24 \mathrm{~h}$ a blistering rash appears) ${ }^{81}$ or traditional remedies such as moxibustion. ${ }^{82}$ Moxibustion is the practice of burning the 'moxa herb' (although other substances may also be used) over the site of the symptoms-for example, around the umbilicus for abdominal pain, on the chest for dyspnoea, etc.

While cigarette burns are recorded in abused children, unfortunately no comparative studies have explicitly documented the pattern found in intentional as opposed to accidental burns. The few case reports giving details, confirm that intentional cigarette burns are circular, approximately 1 $\mathrm{cm}$ in diameter, and may occur on exposed parts of the body. Clinical confusion can arise between cigarette burns and impetigo, but the latter will have scaling around the lesions, and swabs should confirm the presence of the infecting organism. ${ }^{46}$ Disappointingly, there are to date no comparative studies detailing the difference in location, shape or depth between accidental or inflicted cigarette burns, despite the fact that many paediatricians report seeing such cases. Radiation burns, the commonest of which is sunburn in children, raise the dilemma of whether the burn is an 'accident' or 'neglect', particularly in young infants. While it is recognised that neglectful burns are commoner than intentional burns, they can be difficult to identify in practice. ${ }^{71}$ Drawing a distinction between momentary inattention on the parents' part, and inadequate supervision, however, is not always easy. The pattern of burns found in cases of neglect overlap significantly with the pattern found in accidental burns, as these are essentially accidents which could have been prevented, and should have received prompt and appropriate first aid. ${ }^{83}$

\section{IS A TORN LABIAL FRAENUM INDICATIVE OF ABUSE?}

The head is the commonest target organ in child abuse, ${ }^{84}$ with a wide range of oral injuries noted. ${ }^{85}$ A torn labial fraenum has long been held to be pathognomonic of child abuse, particularly in 
younger infants. ${ }^{86}$ Likewise, however, a laceration to the labial fraenum is recognised by dentists as a frequent, and trivial oral injury, occurring owing to a direct blow or fall (eg, from a swing, or falling against a table, etc). In addition, CPR has been noted to be a rare cause of a torn fraenum, ${ }^{87}$ although it is likely that this will be apparent at the time it occurs. In accidental torn fraena, the injury is usually immediately apparent owing to the profuse bloody saliva produced; thus an accidentally torn fraenum should be a memorable event for parents. Unfortunately, there is a lack of comparative studies in the literature to define the distinguishing characteristics of abusive and accidentally torn fraenum. ${ }^{88}$ What is clear, however, is that when a torn fraenum is found in abused children, they are almost invariably very seriously or fatally injured (90\%). ${ }^{46}$ Coexistent injuries are common-in particular, fractures and head injury, ${ }^{89} 90$ abdominal injury ${ }^{87}$ or sexual abuse. ${ }^{91}$ It is clear that while there is no published evidence to say that a torn labial fraenum in isolation is not diagnostic of abuse, it is vitally important to fully investigate any infant presenting with an unexplained torn fraenum, particularly those who are not yet independently mobile. If a torn fraenum is found in a child aged $<2$ years, without adequate explanation, then a full examination and SS should be performed, and if the baby is $<1$ year formal ophthalmological examination and neuroimaging should also be considered. The injury can only be deemed to be 'in isolation' when any other occult injury, or social concerns have been excluded.

Many other oral injuries have been described in abused children, including lacerations to lips or mucosa, dental intrusions, extrusions, ${ }^{88}$ even forcible dental extractions of healthy teeth by parents as a punishment. ${ }^{92}$ None of the injuries has unique distinguishing characteristics, other than an absent or inappropriate history. Some injuries may be very subtle, such as dental microfractures causing brownish/grey discolouration, which may be difficult for a paediatrician to distinguish from dentinogenesis imperfecta or other congenital abnormalities. ${ }^{93}$ Dental neglectcommonly coexists with oral injuries, and may be so severe as to lead to complete extraction of deciduous teeth owing to dental caries. ${ }^{94}$ All children being assessed for suspected abuse should have a full examination of the mouth, and if any abnormal/unusual findings are present, it is important to consult dental colleagues to clarify the full extent of injury and distinguish it from common accidental trauma in children. It is estimated that up to $30 \%$ of children aged $<6$ years sustain accidental dental trauma, with the peak age being 3 years. ${ }^{95}$ Thus any injury found should be evaluated by dentists experienced in the care of children.

\section{WHAT ABDOMINAL INJURIES OCCUR AS A CONSEOUENCE OF PHYSICAL ABUSE?}

While abdominal injuries are rarely recorded in child abuse, they are the second commonest cause of fatal physical abuse. ${ }^{96}$ Abusive abdominal injuries have a higher mortality and morbidity than accidental abdominal trauma, ${ }^{97}$ with solid organ (liver/spleen) and bowel injuries being described almost equally. Many children may have sustained both bowel and solid organ injuries. ${ }^{98}$ Accidental small bowel injuries-in particular, duodenal injuries, are extremely rare in children $<5$ years of age, and if present without explicit accidental trauma, child abuse should be actively excluded. ${ }^{99}$ While up to $60 \%$ of children with abusive abdominal injury may have abdominal bruising, the absence of bruising does not preclude serious injury. Abusive abdominal injury should be considered in children aged $<5$ years, with abdominal signs or symptoms, or where severe coexistent head injury is found and such signs cannot be elicited, or in young children with non-specific abdominal symptoms where other abusive injuries are present. If abdominal injury is thought to be present, the optimal imaging strategy is abdominal CT scan with or without contrast, as ultrasound may miss some injuries. ${ }^{100}$

\section{SUMMARY}

When assessing any child, particularly a younger child, a careful note should be made of injuries that are found. There are well-recognised patterns of typical accidental injuries in children, and likewise there are certain injuries that are strongly associated with abuse. As with any other differential diagnosis that is being considered, investigations must be performed to identify occult injury when abuse is suspected, in conjunction with relevant social enquiries. Clearly an injury can only be deemed to be the result of abuse if appropriate medical explanations have been considered, and excluded appropriately, and where the injury has been evaluated in the context of the history offered, past medical and developmental history, and where a full investigation of social factors and any previous concerns has been conducted.

It is recognised that up to $50 \%$ of children found to have abusive head trauma had been seen by a health practitioner in the month before this, without abuse being recognised. ${ }^{101}$ While no injury makes the diagnosis of abuse in isolation, failing to investigate possibly abusive injuries may miss the only 'window of opportunity', and the next time the child presents it may be fatally injured.

Acknowledgements Grateful thanks to Laura Wain for editorial assistance.

Funding We are grateful for the research grants funding our work, provided by the NSPCC, RCPCH, Welsh Assembly Government and the MRC.

Competing interests None.

Provenance and peer review Commissioned; externally peer reviewed

\section{REFERENCES}

1. Bull L. Children's non-accidental injuries at an accident and emergency department: does the age of the child and the type of injury matter? Accid Emerg Nurs 2006;14:155-9. 
2. Lindell C. Svedin CG. Physical child abuse in Sweden: a study of police reports between 1986 and 1996. Soc Psychiatry Psychiatr Epidemiol 2001;36:150-7.

3. http://www.acf.hhs.gov/programs/cb/pubs/cm07/summary. htm. In.

4. Bullock DP, Koval KJ, Moen KY, et al. Hospitalized cases of child abuse in America: who, what, when, and where. J Pediatr Orthop 2009;29:231-7.

5. Dempsey MP, Orr DJ. Are paediatric burns more common in asylum seekers? An analysis of paediatric burn admissions. Burns 2006;32:242-5.

6. Miller LC, Chan W, Reece RA, et al. Child abuse fatalities among internationally adopted children. Child Maltreat 2007:12:378-80.

7. Govindshenoy M, Spencer N. Abuse of the disabled child a systematic review of population-based studies. Child Care Health Dev 2007;33:552-8.

8. Sidebotham P, Heron J; ALSPAC Study Team. Child maltreatment in the "children of the nineties:" the role of the child. Child Abuse Neg/ 2003;27:337-52.

9. Murty OP, Ming CJ, Ezani MA, et al. Physical injuries in fatal and non-fatal child abuse cases: a review of 16 years with hands on experience of 2 years in Malaysia. Int J Med Toxicol Legal Med 2006;9:33-43.

10. Maguire $\mathbf{S}$. Bruising as an indicator of child abuse: when should I be concerned? Paediatr Child Health 2008;18:545-9.

11. Carpenter RF. The prevalence and distribution of bruising in babies. Arch Dis Child 1999:80:363-6.

12. Nayak K, Spencer N, Shenoy M, et al. How useful is the presence of petechiae in distinguishing non-accidental from accidental injury? Child Abuse Neg/ 2006;30:549-55

13. Sugar NF, Taylor JA, Feldman KW. Bruises in infants and toddlers: those who don't cruise rarely bruise. Puget Sound Pediatric Research Network. Arch Pediatr Adolesc Med 1999;153:399-403.

14. Tush BA. Bruising in healthy 3 -year-old children. Matern Child Nurs J 1982;11:165-79.

15. Feldman KW. The bruised premobile infant: should you evaluate further? Pediatr Emerg Care 2009:25:37-9.

16. Wedgwood J. Childhood bruising. Practitioner 1990:234:598-601.

17. Chang LT, Tsai MC. Craniofacial injuries from slip, trip, and fall accidents of children. J Trauma 2007:63:70-4.

18. Atwal GS, Rutty GN, Carter N, et al. Bruising in non-accidenta head injured children; a retrospective study of the prevalence, distribution and pathological associations in 24 cases. Forensic Sci Int 1998;96:215-30.

19. Dunstan FD, Guildea ZE, Kontos K, et al. A scoring system for bruise patterns: a tool for identifying abuse. Arch Dis Child 2002:86:330-3

20. Brinkmann B, Püschel K, Mätzsch T. Forensic dermatological aspects of the battered child syndrome. Aktuelle Derm 1979;5:217-32.

21. Johnson CF, Showers J. Injury variables in child abuse. Child Abuse Neg/ 1985;9:207-15

22. Feldman KW. Patterned abusive bruises of the buttocks and the pinnae. Pediatrics 1992;90:633-6.

23. Egemen A, Ikizoglu T, Ergör S, et al. Frequency and characteristics of mongolian spots among Turkish children in Aegean region. Turk J Pediatr 2006;48:232-6.

24. Onyeama CO, Lotke M, Edelstein B. Subgaleal hematoma secondary to hair braiding in a 31-month-old child. Pediatr Emerg Care 2009;25:40-1.

25. Mouden LD, Lowe JW, Dixit UB. How to recognize situations that suggest abuse/neglect. Mo Dent J 1992:72:26-9.

26. Maguire S, Mann MK, Sibert J, et al. Can you age bruises accurately in children? A systematic review. Arch Dis Child 2005;90:187-9.

27. Bariciak ED, Plint AC, Gaboury l, et al. Dating of bruises in children: an assessment of physician accuracy. Pediatrics 2003;112:804-7.

28. Munang LA, Leonard PA, Mok JY. Lack of agreement on colour description between clinicians examining childhood bruising. J Clin Forensic Med 2002:9:171-4.

29. Stephenson T, Bialas Y. Estimation of the age of bruising. Arch Dis Child 1996:74:53-5.

30. Duckworth MG, Caspell JJ, Mappus RL, et al. Bruise Chromophore Concentrations Over Time. Medical Imaging
2008: Computer-Aided Diagnosis. Proceedings of the SPIE 2008;6915:69152S-S-11.

31. McMurdy JW, Duffy S, Crawford GP. Monitoring Bruise Age Using Visible Diffuse Reflectance Spectroscopy. Proceeding of the SPIE 2007:6434:26-1 to -8.

32. Wagner GN. Bitemark identification in child abuse cases Pediatr Dent 1986;8:96-100.

33. Freeman AJ, Senn DR, Arendt DM. Seven hundred seventy eight bite marks: analysis by anatomic location, victim and biter demographics, type of crime, and legal disposition. J Forensic Sci 2005;50:1436-43.

34. Lyons RA, Delahunty AM, Kraus D, et al. Children's fractures: a population based study. Inj Prev 1999;5:129-32.

35. Rennie L, Court-Brown CM, Mok JY, et al. The epidemiology of fractures in children. Injury 2007;38:913-22.

36. Worlock P, Stower M, Barbor P. Patterns of fractures in accidental and non-accidental injury in children: a comparative study. Br Med J (Clin Res Ed) 1986;293:100-2.

37. Leventhal JM, Martin KD, Asnes AG. Incidence of fractures attributable to abuse in young hospitalized children: results from analysis of a United States database. Pediatrics 2008;122:599-604.

38. Belfer RA, Klein BL, Orr L. Use of the skeletal survey in the evaluation of child maltreatment. Am J Emerg Med 2001;19:122-4.

39. Merten DF, Radkowski MA, Leonidas JC. The abused child a radiological reappraisal. Radiology 1983;146:377-81.

40. Day F, Clegg S, McPhillips M, et al. A retrospective case series of skeletal surveys in children with suspected non-accidental injury. J Clin Forensic Med 2006;13:55-9.

41. Pierce MC, Bertocci G. Injury biomechanics and child abuse. Annu Rev Biomed Eng 2008;10:85-106.

42. Hui C, Joughin E, Goldstein $\mathrm{S}$, et al. Femoral fractures in children younger than three years: the role of nonaccidental injury. J Pediatr Orthop 2008;28:297-302.

43. Schwend RM, Werth C, Johnston A. Femur shaft fractures in toddlers and young children: rarely from child abuse. J Pediatr Orthop 2000;20:475-81.

44. Kemp AM, Dunstan F, Harrison S, et al. Patterns of skeletal fractures in child abuse: systematic review. BMJ 2008:337:a1518.

45. Dalton HJ, Slovis T, Helfer RE, et al. Undiagnosed abuse in children younger than 3 years with femoral fracture. Am J Dis Child 1990;144:875-8.

46. Welsh Child Protection Systematic Review Group. A series of systematic reviews defining the evidence base for the recognition and investigation of physical child abuse and neglect. http://www.core-info.cf.ac.uk (accessed 29 September 2010).

47. Strait RT, Siegel RM, Shapiro RA. Humeral fractures without obvious etiologies in children less than 3 years of age: when is it abuse? Pediatrics 1995:96:667-71.

48. Farnsworth CL, Silva PD, Mubarak SJ. Etiology of supracondyla humerus fractures. J Pediatr Orthop 1998:18:38-42.

49. Leventhal JM, Thomas SA, Rosenfield NS, et al. Fractures in young children. Distinguishing child abuse from unintentional injuries. Am J Dis Child 1993;147:87-92.

50. Meservy CJ, Towbin R, McLaurin RL, et al. Radiographic characteristics of skull fractures resulting from child abuse. AJR Am J Roentgenol 1987;149:173-5.

51. Reece RM, Sege R. Childhood head injuries: accidental or inflicted? Arch Pediatr Adolesc Med 2000;154:11-15.

52. Hobbs CJ. Skull fracture and the diagnosis of abuse. Arch Dis Child 1984;59:246-52.

53. Barry PW, Hocking MD. Infant rib fracture-birth trauma or non-accidental injury. Arch Dis Child 1993;68:250.

54. Barsness KA, Cha ES, Bensard DD, et al. The positive predictive value of rib fractures as an indicator of nonaccidental trauma in children. J Trauma 2003;54:1107-10.

55. Cadzow SP, Armstrong KL. Rib fractures in infants: red alert! The clinical features, investigations and child protection outcomes. J Paediatr Child Health 2000:36:322-6.

56. Bulloch B, Schubert CJ, Brophy PD, et al. Cause and clinical characteristics of rib fractures in infants. Pediatrics 2000;105:E48.

57. Maguire S, Mann M, John N, et al. Does cardiopulmonary resuscitation cause rib fractures in children? A systematic review. Child Abuse Negl 2006;30:739-51. 
58. The Royal College of Radiologists, The Royal College of Paediatrics and Child Health. Standards for Radiological Investigations of Suspected Non-accidental Injury, 2008.

59. Section on Radiology, American Academy of Pediatrics. Diagnostic Imaging of Child Abuse. Pediatrics 2009:123:1430-5

60. Hansen KK, Prince JS, Nixon GW. Oblique chest views as a routine part of skeletal surveys performed for possible physical abuse - is this practice worthwhile? Child Abuse Neg/ 2008;32:155-9.

61. Ingram JD, Connell J, Hay TC, et al. Oblique radiographs of the chest in nonaccidental trauma. Emerg Radiol 2000;7:42-6.

62. Mandelstam SA, Cook D, Fitzgerald M, et al. Complementary use of radiological skeletal survey and bone scintigraphy in detection of bony injuries in suspected child abuse. Arch Dis Child 2003:88:387-90; discussion 387-90.

63. Kleinman PK, Nimkin K, Spevak MR, et al. Follow-up skeletal surveys in suspected child abuse. AJR Am J Roentgenol 1996;167:893-6.

64. Zimmerman S, Makoroff K, Care M, et al. Utility of follow-up skeletal surveys in suspected child physical abuse evaluations. Child Abuse Neg/ 2005;29:1075-83.

65. Kemp AM, Butler A, Morris S, et al. Which radiological investigations should be performed to identify fractures in suspected child abuse? Clin Radiol 2006;61:723-36.

66. Spinks A, Wasiak J, Cleland H, et al. Ten-year epidemiological study of pediatric burns in Canada. J Burn Care Res 2008;29:482-8

67. Mashreky SR, Rahman A, Chowdhury SM, et al. Epidemiology of childhood burn: yield of largest community based injury survey in Bangladesh. Burns 2008;34:856-62.

68. Showers J, Garrison KM. Burn abuse: a four-year study. J Trauma 1988;28:1581-3.

69. Martin HL. Antecedents of burns and scalds in children Br J Med Psychol 1970;43:39-47.

70. Maguire S, Moynihan S, Mann M, et al. A systematic review of the features that indicate intentional scalds in children. Burns 2008:34:1072-81.

71. Chester DL, Jose RM, Aldlyami E, et al. Non-accidental burns in children-are we neglecting neglect? Burns 2006;32:222-8.

72. Boufous S, Finch C. Epidemiology of scalds in vulnerable groups in New South Wales, Australia, 1998/1999 to 2002/2003. J Burn Care Rehabil 2005:26:320-6.

73. Lowell G, Quinlan K, Gottlieb LJ. Preventing unintentional scald burns: moving beyond tap water. Pediatrics 2008:122:799-804.

74. Dressler DP, Hozid JL. Thermal injury and child abuse: the medical evidence dilemma. J Burn Care Rehabil 2001;22:180-5: discussion 179

75. D'Souza AL, Nelson NG, McKenzie LB. Pediatric burn injuries treated in US emergency departments between 1990 and 2006. Pediatrics 2009:124:1424-30.

76. Nguyen DQ, Tobin S, Dickson WA, et al. Infants under 1 year of age have a significant risk of burn injury. Burns 2008;34:863-7.

77. Wilson Jones $\mathbf{N}$, Wong P, Potokar T. Electric hair straightener burns an epidemiological and thermodynamic study. Burns 2008; 34:521-4.

78. Hobbs CJ. When are burns not accidental? Arch Dis Child 1986:61:357-61.

79. Oates RK. Overturning the diagnosis of child abuse. Arch Dis Child 1984;59:665-6.

80. Porzionato A, Aprile A. Staphylococcal scalded skin syndrome mimicking child abuse by burning. Forensic Sci Int 2007;168:e1-4.
81. Mehta AJ, Statham BN. Phytophotodermatitis mimicking non-accidental injury or self-harm. Eur J Pediatr 2007; 166:751-2.

82. Feldman KW. Pseudoabusive burns in Asian refugees. Am J Dis Child 1984:138:768-9.

83. Hultman CS, Priolo D, Cairns BA, et al. Return to jeopardy: the fate of pediatric burn patients who are victims of abuse and neglect. J Burn Care Rehabil 1998;19:367-76; discussion $366-7$

84. McMahon P, Grossman W, Gaffney M, et al. Soft-tissue injury as an indication of child abuse. J Bone Joint Surg Am 1995: 77:1179-83.

85. Naidoo S. A profile of the oro-facial injuries in child physical abuse at a children's hospital. Child Abuse Negl 2000;24:521-34

86. Macintyre DR, Jones GM, Pinckney RC. The role of the dental practitioner in the management of non-accidental injury to children. Br Dent J 1986;161:108-10.

87. Price EA, Rush LR, Perper JA, et al. Cardiopulmonary resuscitation-related injuries and homicidal blunt abdominal trauma in children. Am J Forensic Med Pathol 2000;21:307-10

88. Maguire S, Hunter B, Hunter L, et al. Diagnosing abuse: a systematic review of torn frenum and other intra-oral injuries. Arch Dis Child 2007:92:1113-17.

89. Datta S, Stoodley N, Jayawant S, et al. Neuroradiological aspects of subdural haemorrhages. Arch Dis Child 2005;90:947-51.

90. Cordner SM, Burke MP, Dodd MJ, et al. Issues in child homicides: 11 cases. Leg Med (Tokyo) 2001;3:95-103.

91. Hobbs CJ, Wynne JM. The sexually abused battered child. Arch Dis Child 1990:65:423-7.

92. Carrotte PV. An unusual case of child abuse. Br Dent $J$ 1990;168:444-5.

93. Wright JT, Thornton JB. Osteogenesis imperfecta with dentinogenesis imperfecta: a mistaken case of child abuse. Pediatr Dent 1983;5:207-9.

94. Donly KJ, Nowak AJ. Maxillofacial, Neck, and Dental Lesions of Child Abuse. Philadelphia, Pennsylvania, USA: Lea \& Febiger, 1994.

95. Soriano EP, Caldas Ade F Jr, Diniz De Carvalho MV, et al. Prevalence and risk factors related to traumatic dental injuries in Brazilian schoolchildren. Dent Traumatol 2007;23:232-40.

96. Collins KA Nichols CA. A decade of pediatric homicide: a retrospective study at the Medical University of South Carolina. Am J Forensic Med Pathol 1999;20:169-72

97. Wood J, Rubin DM, Nance ML, et al. Distinguishing inflicted versus accidental abdominal injuries in young children. J Trauma 2005;59:1203-8.

98. $\mathbf{N g ~ C S}$, Hall CM, Shaw DG. The range of visceral manifestations of non-accidental injury. Arch Dis Child 1997;17:167-74.

99. Champion MP, Richards CA, Boddy SA, et al. Duodenal perforation: a diagnostic pitfall in non-accidental injury. Arch Dis Child 2002;87:432-3

100. Mirvis SE, Gens DR, Shanmuganathan K. Rupture of the bowel after blunt abdominal trauma: diagnosis with CT. AJR Am J Roentgenol 1992;159:1217-21.

101. Coles L, Kemp A. Cues and clues to preventing shaken baby syndrome. Community Pract 2003:76:459-63. 